\title{
Matter transfer and land use by cattle in a dehesa ecosystem of Central Spain
}

\author{
A. Gómez-Sal, ${ }^{1}$ M. A. Rodríguez ${ }^{1} \&$ J. M. De Miguel $^{2}$ \\ ${ }^{1}$ Instituto Pirenaico de Ecologia (CSIC), Ap. 202, 50080 Zaragoza, Spain; ${ }^{2}$ Dpto. Ecologia, Universidad \\ Complutense, 28040 Madrid, Spain
}

Accepted 8.11.1991

Keywords: Cattle behaviour, Dehesa pastureland, Distribution of dung, Habitat preference

\begin{abstract}
The transfer of matter by cattle in a 'dehesa' patureland in Central Spain has been quantified by mapping the distribution of dung and different types of cattle behaviour in several areas distinguished by their geomorphological position, vegetation structure and management regime.

Cattle show a clear preference for feeding and dung depositing in the low parts of the estate. This leads to an increase in the productivity and a rapid recycling of nutrients in the pasture communities of these areas. Comparing the relative importance of both processes in each vegetational unit, dung accumulation is greater in the higher zones, while in the lower areas biomass consumption is more important. This means that movement of matter by cattle tends to favour the higher ground, in a contrary direction to the downward leaching of nutrients and related processes. In the studied dehesa, this phenomena represents an 'exploitation' factor of the lowland areas, which maintains productive pasture communities more immature in successional terms, by the higher woodland areas, less grazed and with low turnover. This result supports claims made in other studies that animal activity - assessed in our case by the relative impacts of herbivory and dung depositions - connect adjacent ecosystems and thus tends to improve the net energy balance of the more successionally mature part of the system.

Livestock movements differ in their spatial pattern during different periods of the year: dispersing in spring and becoming more concentrated and predictable during winter. The clear seasonal differences of herbaceous production in Mediterranean climates and the management activities (basically ploughing, tree pruning and fodder supply) are the main causes of this pattern.
\end{abstract}

Abbreviations: $\mathrm{PI}=$ Preference Index

Nomenclature: Tutin et al. 1964-1980. Flora Europaea.

\section{Introduction}

The role of animals in the control of energy flow in heterogeneous environments, in particular their influence on vegetation structure and dynamics, is an important issue in ecology. Animals can be considered to be 'biotic vectors' which move matter and energy in the landscape, thus interconnecting different sybsystems (Forman 1981; Wiens et al. 1985; Forman \& Godron 1986). This 
action can counterbalance the abiotic flow of matter resulting from leaching and other related processes, and adds complexity to the ecosystem dynamics. In theory, the habitat preferences of animals may accentuate or buffer existing imbalances in the import and export of biomass and nutrients between parts of the system, thus directly acting on their dynamics.

In pasture ecosystems, studies of matter transfer by livestock have mainly examined processes of differential accumulation of dung and its beneficial or detrimental effects on herbage productivity and quality (eg., Dean et al. 1975; Arnold \& Dudzinski 1978; Edward \& Hollis 1982). Studies which analyze the relative co-occurrence of biomass consumption and dung accumulation are less common. The present paper is aimed at detecting imbalances in the distribution of biomass and nutrients which may explain the role of livestock in matter transfer in a Spanish 'dehesa' an open savannah-like Holm oak woodland (Quercus rotundifolia) (Balcells \& Gómez 1979).

The accumulation of different types of dung, and the intensity of grazing and other types of cattle behaviour have been calculated in several vegetational units with within the dehesa. The study has two aims: i) to describe the degree of spatial coincidence between dung accumulation and feeding behaviour of cattle; and ii) to highlight the effect of any net export or import of matter on the vegetation dynamics previously analyzed in the studied territory (see Casado et al. 1985; Gómez-Sal et al. 1986).

\section{Study area}

The study was carried out near Madrid on a 3000 ha estate, which is part of the 'El Pardo' area, now protected as a Natural Park. The estate has been used for 15 years by the Ecology Departments of the Complutense and Autonoma Universities of Madrid to study the spatial and temporal dynamics of mediterranean pastures during succession (Pineda et al. $1981 \mathrm{a}, \mathrm{b}$; Peco et al. 1983; Sterling et al. 1983; Gómez-Sal et al. 1986: Pineda \& Peco 1988), and the effects of cattle (De Miguel et al. 1986; Gómez-Sal \& De Miguel et al. 1989).

The wooded vegetation of the estate comprises woodlands and scattered trees of holm oak in the high and intermediate zones, and dispersed ash trees (Fraxinus angustifolia) in the lowland areas. Pastures are dominated by therophytes, and scrub vegetation consists mainly of holm oak in shrub form together with Cistus ladanifer, Santolina rosmarinifolia, Thymus spp., Daphne gnidium and Phillyrea angustifolia. The lithological substratum consists of granitic and arkosic sediments giving an undulating relief, with altitude ranging from 610 to $720 \mathrm{~m}$. The climate is essentially Continental-mediterranean, with strong seasonal contrasts. Mean annual precipitation is $600 \mathrm{~mm}$. The mean minimum and maximum temperatures range from $-7^{\circ} \mathrm{C}$ to $37^{\circ} \mathrm{C}$ respectively. Only three months are guaranteed frost free, while for five months frosts are normal, the remainder having occasional frosts.

About 400 free-ranging cattle are grazed on the estate. The populations of fallow deer (Dama dama L.), red deer (Cervus elaphus L.) and rabbits (Orictolagus cuniculus L.) are hunted. During some periods in both summer and winter, cattle require an additional supply of fodder. Many parts of the estate are ploughed periodically to eliminate thickets and encourage the growth of pasture, leading to a mosaic of communities of differing successional states. Areas with very different successional status - from pastures and scrubs to cleared and dense woodlands - occur in close proximity.

A previous sectorization of the estate serves as a reference for the study of spatial relationships between the variables under consideration. Clustering was used to divide the estate into four homogeneous sectors in terms of geomorphology, vegetation structure and ploughing intensity, which strongly influence the variability of herbaceous communities (see De Miguel 1989). The location of the sectors closely fits the geomorphological gradient of the territory. Table 1 shows the variables and landscape models which characterize the four sectors. 
Table 1. Characteristics and synthetic models of the landscape of the four sectors used in the study of matter transfer and cattle behaviour in the estate.

\begin{tabular}{|c|c|c|c|c|}
\hline Sector & 1 & 2 & 3 & 4 \\
\hline Geomorphological position & Recent alluvials & $\begin{array}{l}\text { Low zones } \\
\text { Terraces }\end{array}$ & $\begin{array}{l}\text { Intermediate zones } \\
\text { Slopes and hills }\end{array}$ & Upper zones \\
\hline Ploughing & Unploughed & Infrequent ploughing & Frequent ploughing & Unploughed \\
\hline Dominant relief & Flat & Flat & Undulating & Undulating and Steep \\
\hline Vegetation structure & $\begin{array}{l}\text { Cleared gallery forest, } \\
\text { grasslands and } \\
\text { dispersed ash }\end{array}$ & $\begin{array}{l}\text { Pastures with scattered } \\
\text { holm oak }\end{array}$ & $\begin{array}{l}\text { Open holm oak forest } \\
\text { alternating with } \\
\text { pastures and scrub }\end{array}$ & $\begin{array}{l}\text { Dense holm oak forest } \\
\text { with scrub }\end{array}$ \\
\hline Herbaceous cover & Very high $>75^{\circ}$ & High $50-75 \%$ & $10-50 \%$ & Very low $<10^{\circ}$ \\
\hline Shrub cover & Very low $<10^{\circ}$ o & Very low $<10^{\circ}$ & $10-50^{\circ}$ & High $50-75^{\circ}$ \\
\hline Landscape scheme & & & & \\
\hline
\end{tabular}

\section{Methods}

393 sites for sampling dung were chosen at random within the four sectors identified in Table 1. In each sector the number of samples was proportional to its respective area. Sampling took place in July, coinciding with a floristic sampling. At this time of the year the characteristics of dung (most of them dry and consistent) makes its cover an appropriate estimate of abundance. Three types of dung were identified: from cattle, from rabbits and from other animals (primarily red and fallow deer). At each site, the mean cover of each type of dung was recorded in four $1 \mathrm{~m} \times 1 \mathrm{~m}$ quadrats.

Parallel to this study, the behaviour of cattle was surveyed in 35 sampling days evenly distributed throughout one and a half years (1983-84). Every day, the behaviour of cattle was recorded at $10 \mathrm{~min}$ intervals from sunrise to sunset. Prior to this first observation, an animal was chosen at random to serve as guide during the rest of the day. Only the cattle in a $50 \mathrm{~m}$ radius around this animal was considered. A maximum of 10 animals was taken into account on each observation, which implicated noting the number of animals which were involving in certain basic activities: grazing, browsing, resting-ruminating and travel- ling (Hafez \& Schein 1969; Arnold \& Dudzinski 1978). The exact spatial location of the animals considered in each observation was noted and each morning and afternoon, an itinerary through the whole estate was made by car to map the location of all the cattle herds found.

The numerical treatments were based on the Preference Index (PI) proposed by Hunter (1962) and used by other authors for similar studies (Pratt et al. 1986; Putman et al. 1987). This index relates the relative abundance of the variables in each sector of the state to the relative cover of the sector. This gives an idea of the degree of preference of the sector by the variable (percentage of behaviour activity or percentage cover of a type of dung). The relation can be described as:

$$
\mathrm{PI}=\mathrm{Vi} / \mathrm{Ai},
$$

where $\mathrm{Vi}$ is the percentage of the variable in sector $\mathrm{i}$ compared to the whole of the estate, and $\mathrm{Ai}$ is the percentage of the estate area occupied by sector $\mathrm{i}$.

The balance of matter transfer by cattle in each sector is evaluated by means of quotients which compare the relative abundance of both cattle dung and feeding activities (percentage of grazing + browsing). This is based on the premise that in a random sample the frequency of ob- 
served feeding behaviour is proportional to, and thus indicative of, the amount of biomass removed.

\section{Results and discussion}

\section{Territorial imbalances between feeding behaviour and matter accumulation processes}

Table 2 shows the abundance of different types of dung and behavioural activities in all of the sectors. The results show the different roles of each sector in relation to both the receipt and supply of matter, and in terms of where different cattle activities are carried out. The contrast between sectors which are preferred by cattle for extractive activities (grazing and browsing), and others in which dung accumulation predominates provides an idea of the main imbalances in the import and export of biomass and nutrients.

The degree of overall usage of the sectors by the cattle ('all activities' in Table 2) is associated with the geomorphological variation of the estate. Number of animals is clearly greater in sectors of the lowland. The highest percentages and PI val- ues are found in sector 1 and the lowest in sector 4. In a semiarid Mediterranean climate, the moisture and herbaceous production gradients associated with geomorphology affect the trends in animal distribution (Arnold \& Dudzinski 1978; Gómez-Sal \& De Miguel 1989).

If only the extractive activities (grazing + browsing in Table 2) by cattle are considered, there is also a clear association with the geomorphological gradient. The lower the position on the relief, the higher the percentage and the PI values, indicating greater feeding activity per surface area in the lowland areas. However, there is a significant difference between sectors as suppliers of different types of food. While the lowland zones are used more for grazing, i.e. the extraction of herbaceous biomass, the upland sectors (sectors 3 and 4 ) are the main suppliers of more fibrous of lignified biomass, such as leaves and small holm oak branches, which are consumed by cattle during periods of grass shortage (high browsing values). The type of vegetation characteristic of each sector is responsible for these preferences. Traditional management has influenced the structure of the different types of dehesa vegetation, with denser woodland communities in the upper zones

Table 2. (a) Percentage of obscrved animals involved in each type of behaviour. "All activities" includes some types of behaviour not considered in this study. (b) Percentage of the surface of the estate covered by each type of dung. $\left({ }^{\circ}\right)$ Relative importance of the variables in the sectors. (PI) Preference Index.

\begin{tabular}{|c|c|c|c|c|c|c|c|c|c|}
\hline \multicolumn{2}{|l|}{ Sector number } & \multicolumn{2}{|l|}{1} & \multicolumn{2}{|l|}{2} & \multicolumn{2}{|l|}{3} & \multicolumn{2}{|l|}{4} \\
\hline \multicolumn{2}{|l|}{ Area percentage } & \multicolumn{2}{|c|}{14.0} & \multicolumn{2}{|c|}{27.1} & \multicolumn{2}{|c|}{25.6} & \multicolumn{2}{|c|}{32.8} \\
\hline & & 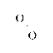 & PI & $\because$ & PI & $"$ & PI & $\because$ & PI \\
\hline & $\mathrm{a}$ & & & & & & & & \\
\hline All activities & $100^{\circ}$ & 44 & 3.1 & 35 & 1.3 & 13 & 0.5 & 7 & 0.2 \\
\hline Grazing + browsing & $26 \%$ & 27 & 1.9 & 33 & 1.2 & 25 & 1.0 & 15 & 0.5 \\
\hline Grazing & $21 \%$ & 30 & 2.1 & 35 & 1.3 & 26 & 1.0 & 9 & 0.3 \\
\hline Browsing & $5^{\circ}$ & 14 & 1.0 & 28 & 1.0 & 22 & 0.9 & 35 & 1.1 \\
\hline Resting and ruminating & $47^{\circ} \circ$ & 35 & 2.5 & 50 & 1.8 & 10 & 0.4 & 5 & 0.2 \\
\hline \multirow[t]{2}{*}{ Travelling } & $9^{\circ}$ & 37 & 2.6 & 32 & 1.2 & 22 & 0.9 & 9 & 0.3 \\
\hline & $\mathrm{b}$ & & & & & & & & \\
\hline Cattle dungs & $4_{0}^{\circ}$ & 22 & 1.6 & 37 & 1.4 & 22 & 0.9 & 19 & 0.6 \\
\hline Rabbit droppings & $10^{\circ}$ & 19 & 1.4 & 35 & 1.3 & 26 & 1.0 & 20 & 0.6 \\
\hline Other dungs & $4^{\circ}$ & 26 & 1.9 & 19 & 0.7 & 21 & 0.8 & 34 & 1.0 \\
\hline
\end{tabular}


and the predominance of pastures with scattered tree cover in the lower zones. This greatly affects the movement of animals and the transfer of matter.

The uneven distribution of dung in the sectors may indicate the direction of nutrients moved by animals as a consequence of their feeding habits. The greatest accumulation of cattle dung occurs in the lowest sectors of the estate (sectors 1 and 2 show the highest values of PI and almost $60 \%$ of the total dung cover). In addition, the sector having the lowest alluvial terrain (sector 1) receives the greatest amount of dung per surface unit; PI reaches 1.6. A similar distribution pattern is also observed for rabbit droppings - closely related to geomorphology - which increases the importance of the low areas as dung reception areas. This is coherent with the fact that rabbits are active grazers, preferentially consumers of green herbage.

In contrast, the variable 'other dungs' shows a more selective trend. Red deer and fallow deer dung appears preferentially in lowland pastures ( sector $1, \mathrm{PI}=1.9$ ), shows a light reject by intermediate areas (sector 2 and 3), and is indifferent to the dense woodlands (sector $4, \mathrm{PI}=1.0$ ). It may be assumed that this result may be mainly due to red deer, because of its browsing nature. Taking into account that dense woodlands are negatively related with the other variables $\mathrm{PI}>1$ (types of behaviour and dungs), this suggests that the behaviour of red deer exerts an appreciable action in buffering the existing imbalances in the distribution of fertility, which is clearly in excess in the lowlands.

In general, the results of the distribution of 'all dungs' shows correspondence with downward leaching of nutrient and related processes. This leads to a high input of matter in the lowland pastures of the estate, which may explain some of their successional tendencies. According to Casado et al. (1985), these communities tend to increase biomass production, turnover and diversity during successional development after ploughing, which occurs parallel to a progressive increase of grazing pressure. These tendencies are only possible if the input of nutrients is enough to compensate the high biomass outputs caused by herbivores, and suggests that the intense exploitation of lowland pastures does not result in a significant export of matter to other ecosystems. Indeed a high percentage of matter appears to be recycled 'in situ' and is also augmented by supply from other zones. Grazing thus favours a rapid nutrient cycle in areas with higher fertility (more adequate water supply, deep soil). This process creates an environmental framework that permits the co-existence of areas with a rapid renewal of biomass, with areas having relatively high levels of organization. Analyzing the dynamics of these periodically ploughed pastures, the dehesa under study may be considered as being formed by multiple active borders, through which a highly dynamic exchange of matter and propagules occurs (Gómez-Sal et al. 1986, Pineda \& Peco 1988).

At the scale of detail adopted in the present study - i.e. that which affects the whole estate the balance and transfer of matter can be assessed by quotients that compare the relative abundance of cattle dung and feeding activities grazing + browsing - (see Table 3 ). The results of considering the four sectors separately do not indicate a clear association with the geomorphological gradient on which the estate occurs. On the scale of detail chosen in the sectorization of the estate, the transfer of matter by cattle shows a complex spatial pattern which is difficult to interpret. The lowest and intermediate relief zones (sectors 1 and 3 ) show a predominance of biomass extraction as opposed to dung deposit (values clearly under 1.0). On the other hand, sector 2

Table 3. (X) Percentage of dung accumulation, (Y) percentages of feeding activities, $(\mathrm{X} / \mathrm{Y})$ quotient comparing the relative abundance of both variables from different posibilities of joining adjacent sectors.

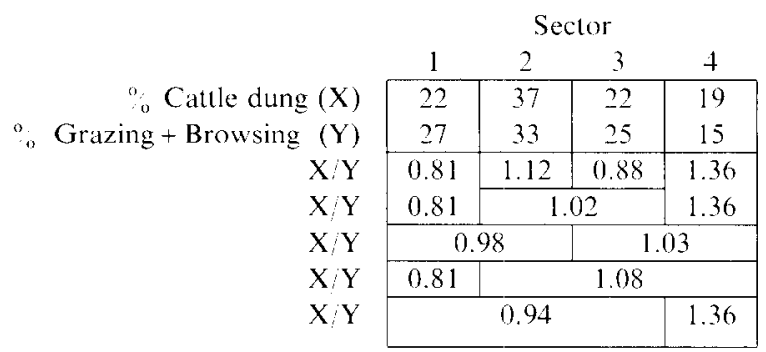


and especially sector 4 - highest zone - show a favorable balance of dung accumulation.

However a reclassification of the sectors of the estate enables a clear trend of variation in the net flows of matter to be detected. The new sectorization is achieved by joining spatially adjacent sectors. This is appropriate in the present case as the sectors are differentiated according to a geomorphological gradient.

Dividing the estate into three sectors $(1,2+3$, and 4) so that the differences between the most contrasted sectors ( 1 and 4 ) stand out, the new values of the quotients show a clear tendency to increase with height on the geomorphological gradient. The same trend is also observed in the three cases in which the territory is subdivided into two different sectors. These divisions are also appropriate as they join sectors with different degrees of man-induced changes: greater in the lower sectors, lesser in the higher areas.

The results confirm observations made in previous studies which have examined the dynamics of active borders, where animal-associated matter flows tend to exploit the most productive subsystem (with a high turnover) to the benefit of the less productive one (with lower turnover) (Margalef 1963, 1974; Turner \& Bratton 1987). Nev- ertheless, in our case the peculiar geomorphological position of the interconnected communities introduces interesting modifications to the functional interrelationships of both subsystems. The net flow of matter by cattle from the lower, more productive zones to the higher, less productive areas may be countered by the general gravitational flow down the slope which tends to return the extracted nutrients to the lower areas. This behaviour, favoured by the peculiar structure of the dehesa vegetation, permits the distribution of the nutrients throughout the estate while not substantially affecting the production potential of the lowland pastures which always have a highly favourable balance in absolute terms (total supply per surface area).

Seasonal variation in the movement of matter by cattle

The spatial pattern of matter transport by cattle varies seasonally. Figure 1 shows the location of cattle on typical spring and winter days. These are the most highly contrasted seasons in terms of cattle behaviour (Gómez-Sal \& De Miguel 1989). Table 4 shows the percentages of behav-

Table 4. Relative importance (percentage and PI) of behaviour variables in each sector of the estate in spring and winter. See Table 2 for details

\begin{tabular}{|c|c|c|c|c|c|c|c|c|c|}
\hline & \multirow[t]{2}{*}{ a } & \multicolumn{2}{|c|}{ Sector 1} & \multicolumn{2}{|c|}{ Sector 2} & \multicolumn{2}{|c|}{ Sector 3} & \multicolumn{2}{|c|}{ Sector 4} \\
\hline & & $\%$ & PI & 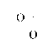 & PI & $\%$ & PI & $\%$ & $\mathrm{Pi}$ \\
\hline \multicolumn{10}{|l|}{ Spring days } \\
\hline All activities & 100 & 23 & 1.6 & 33 & 1.2 & 16 & 0.6 & 27 & 0.8 \\
\hline Grazing & 50 & 26 & 1.9 & 27 & 1.0 & 34 & 1.3 & 13 & 0.4 \\
\hline Browsing & 1 & 14 & 1.0 & 36 & 1.3 & 3 & 0.1 & 47 & 1.4 \\
\hline Resting-ruminating & 25 & 13 & 0.9 & 45 & 1.7 & 15 & 0.6 & 26 & 0.8 \\
\hline Travelling & 11 & 44 & 3.1 & 29 & 1.1 & 14 & 0.6 & 14 & 0.4 \\
\hline \multicolumn{10}{|l|}{ Winter days } \\
\hline All activities & 100 & 25 & 1.8 & 42 & 1.6 & 26 & 1.0 & 8 & 0.2 \\
\hline Grazing & 5 & 7 & 0.5 & 58 & 2.1 & 15 & 0.6 & 21 & 0.6 \\
\hline Browsing & 4 & 0 & 0.0 & 21 & 0.8 & 9 & 0.4 & 69 & 2.1 \\
\hline Resting-ruminating & 46 & 34 & 2.4 & 42 & 1.6 & 22 & 0.9 & 2 & 0.1 \\
\hline Travelling & 10 & 25 & 1.8 & 36 & 1.3 & 24 & 1.0 & 15 & 0.5 \\
\hline
\end{tabular}



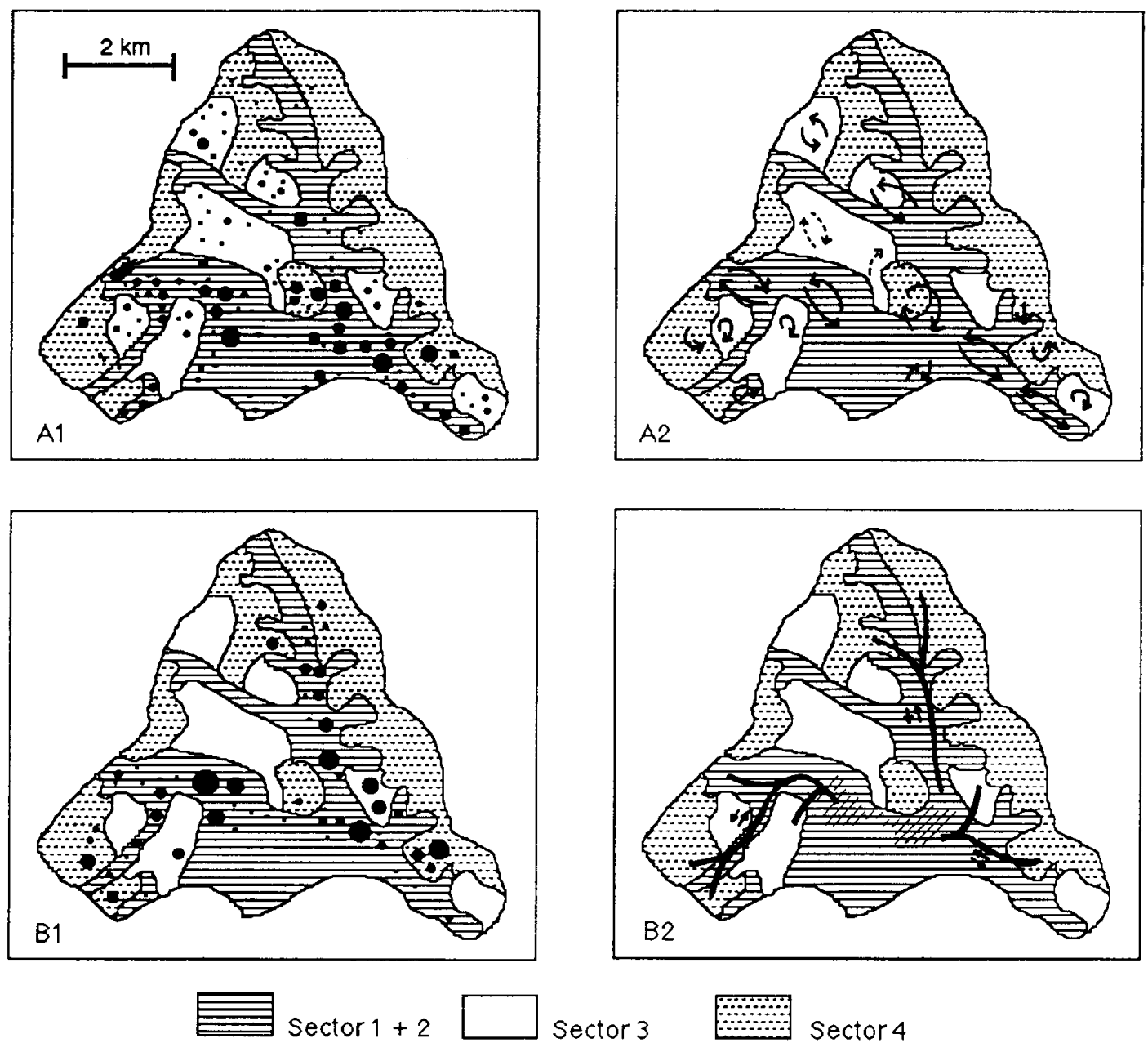

Fig. I. Spatial distribution of cattle on the estate. A) Spring, B) winter. 1) Points indicate the abundance of animals observed in each place on the estate. 2) Arrow positions indicate the paths and areas of the estate used by cattle herds. Oblique lines in B2 indicate feeding supply areas.

ioural activities and PI values in each sector in the two seasons. The seasonal differences in the spatial distribution of animals affect the extent of the transfer processes between systems.

In spring, herbaceous pasture is available throughout the estate and there is a clear dispersion of the cattle. Feeding activities are highly segregated spatially. Sectors 1 and 3 are preferred by cattle for grazing ( $\mathrm{PI}=1.9$ and 1.3 respectively) while browsing mainly occurs in sectors 4 and $3(\mathrm{PI}=1.4$ and 1.3$)$. The latter sector is also preferred for resting and ruminating. It attracts a large number of animals, leading to a high concentration of dung. The dispersion of the animals in spring favours a more homogeneous distribution of organic matter over the estate.
In winter, the activities of the cattle are more periodical and more clearly defined territorially. Daily visits to the area where fodder is placed and subsequent dispersal movements affect the whole estate and are a remarkable feature of this season. This favours a simple flow of matter. A noticeable preference for particular sectors is particularly clear in extractive activities. Grazing mainly occurs in sector $2(\mathrm{PI}=2.1)$ where $58 \%$ of this activity is located, while browsing is greatest in sector $4(\mathrm{PI}=2.1)$. Both activities occur in specific locations within the two sectors. Grazing takes place in areas sheltered from the wind at the bottom of gullies, the only locations with profitable grass production and pasture (mostly Agrostis castellana and Festuca ampla). Browsing tends to 
be concentrated in dense holm oak scrub and woodland areas, where animals gather in the late afternoon to shelter against the low night temperatures.

Winter management (fodder supply in specific zones) forces a transfer between spatially distant areas. The excessive concentration of cattle in certain places leads to heavy eutrophication, causing low quality pastures containing Urtica urens, Chenopodium opulifolium, Stellaria media and Eryngium campestre.

\section{Importance of paths in matter transfer}

Cattle movement follows a network of hierarchical paths with a varying intensity of trampling pressure. The structure of the network influences the possibility of extraction, transfer and accumulation of matter in each sector. Understanding these aspects is important for guiding cattle towards certain areas by means of management activities (location of fodder, salt and water supply points) and to thereby achieve more efficient use of the dehesa.

The schematic maps in Figure 1 show the routes followed by the cattle in their spring and winter movements. The thickness of the arrows represents the frequency of trampling in the paths.

The lowest sectors ( 1 and 2 ) receive the majority of the movements (see travelling in Table 4) in the two seasons, with high percentages and PI. However the spatial pattern of this activity varies considerably with season. In spring, usage frequency is comparable in all the routes and cattle travel a shorter average distance. In winter, fewer routes are used but the journeys are longer.

In spring, the greater dispersion of the animals determines a more even usage of the path network. The high pasture availability throughout the estate favours the existence of small herds in confined areas, and cattle seem to adopt a territorial like behaviour. On the other hand, the winter results can be explained by the daily concentration of cattle in specific points (fodder supply zones) from which they travel in the evening to the dense woodlands to browse and to shelter for the night.

\section{Conclusions}

The analysis of the correspondence between the spatial distribution of both dung accumulation and feeding activities of cattle, is a reliable means of pinpointing the importance of animals as active vectors of matter transfer in pasturelands. The relationships between the variables provide an understanding of the direction and importance of matter flows between subsystems of the dehesa. The analysis also permits an appreciation of imbalances in the import and export of biomass and nutrients among sectors of the estate.

Vegetation structure, closely related to geomorphology in the studied dehesa, and created to a great extent by specific management, seems to be the main factor which conditions the transfer of matter by cattle. In absolute terms, the distribution of dung indicates the importance of nutrient accumulation in the most productive pastures of the lowland zones. In these communities, grazing leads to a faster recycling of nutrients, and permits the maintenance of a high productivity.

Dung accumulation and feeding (grazing + browsing) have different relative importance in the four differentiated sectors. Dung accumulation has a relatively high importance in the higher woodlands, while in the lowland pastures biomass consumption predominates. $\Lambda$ s a result the dehesa under consideration can be divided into two large subsystems with differing degrees of maturity. An uneven interchange of matter is established between both parts of the system: whereas the active transport (land use by cattle) favours the former in relative terms, the passive mechanisms (e.g. leaching) favour the more dynamic and productive areas (low zones of pasture with scattered trees). This imbalance represents a factor in the exploitation of the less successionally mature part of the system by the more mature one. Similar results have been found in other asymmetrical borders (borders connecting ecosystems in different successional stages). $\Lambda$ particular feature of the present case is that the transfer of matter by cattle tends to be countered by the geomorphological position of the main sub- 
systems. Thus, part of the nutrients carried by cattle to the high zones, are returned to the lowland pastures by leaching and other related processes.

The success of the dehesa as a system of livestock production is largely based on the maintenance of both subsystems (stabilizing and productive), which thus ensure the persistence of the whole system. The existence in the low and intermediate zones of a mosaic of scattered trees (holm oaks, and ash in the moister areas) is also a stabilizing mechanism acting in a similar fashion to woodlands of the high sectors.

The spatial patterns of the transfer of matter by cattle differ seasonally. They are related to the availability of grass and to the management of the estate. In spring, the matter flows are more dispersed due to the high availability of grass throughout the estate, which favour a more dispersed cattle distribution, with a large number of small cattle herds. In winter, the matter flows connecting specific areas of the estate, are more concentrated and better defined. The low availability of grass and the need for fodder supply favour a clear concentration of animals in particular, highly distant areas, which are interconnected by long itineraries followed by the cattle every day.

The results of the present study suggest that animal behaviour adding to traditional management, in particular ploughing, whose effects on vegetation dynamics have been studied in previous work (Pineda et al. $1981 \mathrm{a}, \mathrm{b}$; De Miguel et al. 1986; Gómez-Sal et al. 1986; Pineda \& Peco 1988), maintain the dehesa as an ecosystem formed by multiple active borders, through which highly dynamic exchanges of matter and propagules occur.

The characteristic structure of the vegetation in the dehesa, comprising complementary woodlands, pastures and savannah-like forests with scattered trees, maintains both stabilizing and productive components, and is thus an indispensable condition for the persistence of the whole livestock production system.

\section{Acknowledgements}

The authors would like to thank Dr. J. G. Hodgson from Department of Plant Sciences, University of Sheffield, in reviewing and commenting on the original manuscript. This study was possible due to the financial support of the Spanish Scientific and Technical Research Commission ( $\mathrm{C} \wedge$ ICYT), Project PB87-0451 and the collaboration of the proprietor of the estate GESTINCO S.L.

\section{References}

Arnold, G. W. \& Dudzinski, M. L. 1978. Ethology of freeranging domestic animals. Elsevier, New York.

Balcells, E. \& Gómez, J. M. (eds) 1975. Estudio integrado y multidisciplinario de la dehesa salmantina. Fasc. 1-4. Proyecto $506 \mathrm{MaB}$. UNESCO.

Casado, M. A., De Miguel, J. M., Sterling, A.. Peco, B.. Galiano, E. F. \& Pineda, F. D. 1985. Production and spatial structure of Mediterranean pastures in different stages of ecological succession. Vegetatio 64: 75-86.

Dean, R., Ellis, J. E., Rice, R. W. \& Bement, R. E. 1975. Nutrient removal by cattle from a short grass prairic. J. Appl. Ecol. 12: 25-29.

De Miguel, J. M., Casado, M. A., Gómez-Sal, A. \& Pineda, F. D. 1986. Herbivores influence on the quality and structural evolution on a dehesa pasture in central Spain. In F. M. Borba \& J. M. Abreu (eds), Grassland facing the energy crisis. S.P.P.S., Lisboa: 134-138.

De Miguel. J. M. 1989. Estructura de un sistema silvopastoral de dehesa. Tesis docioral. Facultad de Biología. Universidad Complutense, Madrid.

Edwards, P. J. \& Hollis, S. 1982. The distribution of excreta on New Forest grassland used by cattle, ponies and deer. J. Appl. Ecol. 19: 953-964.

Forman, R. T. T. 1981. Interaction among landscape elements: A core of landscape ecology. Int. Congr. Neth. Soc. Landscape Ecol. Veldhovenm. Proceedings 35-48.

Forman, R. T. T. \& Godron, M. 1986. Landscape Ecology. Wiley \& Sons, London.

Gómez-Sal, A., De Miguel, J. M., Casado, M. A. \& Pineda, F. D. 1986. Successional changes in the morphology and ecological responses of a grazed pasture ecosystem in Central Spain. Vegetatio 67: 33-44.

Gómez-Sal, A. \& De Miguel, J. M. 1989. Implicaciones ecológicas en el aprovechamiento de dehesas. In: Lnesco (ed), Seminaire sur dehesas et systemes agro-silvo-pastoraux similaires. MaB. Abstracts, 98.

Hafez, E. S. E. \& Schein, H. W. 1969. The behaviour of cattle. In: E. S. E. Hafez (ed), The behaviour of domestic animals. Baillere-Tindall \& Casell, London: 247-296.

Hunter. R. F. 1962. Hill sheep and their pasture: a study of 
sheep grazing in South East Scotland. J. Ecol. 50: 651680 .

Margalef. R. 1963. On certain unifying principles in ecology. Am. Naturalist 97: 357-374.

Margalef. R. 1974. Ecologia. Omega, Barcelona.

Peco. B., Levassor, C.. Casado, M. A. \& Pineda, F. D. 1983. Influences météorologique el géomorphologique sur la succession de paturages de thérophytes méditerranéennes. Ecol. Medit. 9 (1): 63-76.

Pineda. F. D., Nicolás, J. P., Pou. A. \& Galiano, E. F. 1981a. Ecological succession in oligotrophic pastures of Central Spain. Vegetatio 44: $165-175$.

Pineda, F. D.. Nicolás, J. P.. Ruiz. M. \& Bernáldez, F. G. 1981b. Succession, diversité el amplitude de niche dans les paturages du centre de la péninsule ibérique. Vegetatio 47 : $267-277$

Pineda. F. D. \& Pceo. B. 1988. Pastizales adehesados del area de El Pardo. Mundo Científico (La Recherche) 79 . $386-395$
Pratt, R. M., Putman, R. J., Ekins, J. R. \& Edwards, P. J. 1986. Use of habitat by frec-ranging cattle and ponies in the New Forest, southern England. J. Appl. Ecol. 23: 539 557.

Putman, R. J., Pratt, R. M.. Ekins, J. R. \& Edwards, P. J. 1987. Food and feeding behaviour of cattle and ponies in the New Forest, Hampshire. J. Appl. Ecol. 24: 369380 .

Sterling, A., Peco, B., Casado, M. A. \& Pineda, F. D. 1983. Microtopography and floristic variation on the ecological succession of grasslands. Oikos 42: 334-342.

Turner, M. G. \& Bratton, S. P. 1987. Fire, grazing and the landscape heterogeneity of a Georgia Barrier Island. In: M. G. Turner (ed), Landscape heterogeneity and disturbance. Ecological Studies 64. Springer-Verlag, New York, pp. 85-101.

Wiens, J. A.. Crawford, C. S. \& Gosz, J. R. 1985. Boundary dynamics: a conceptual framework for studying landscape ecosystems. Oikos 45: 42l-427. 